\title{
Severe hypercalcaemia in sarcoidosis: Is Vitamin D replacement safe?
}

Ahmed El-Laboudi, Rozana Ramli, Emma Hatfield

\section{BACKGROUND}

- There has been a wide interest in the role of vitamin $D$ in extraskeletal systems with subsequent increased access to vitamin $D$ supplementation.

- However, in patients with granulomatous disease, peripheral activation of vitamin $D$ raises the possible risk of vitamin $D$ toxicity in patients receiving Vitamin D supplementation.

\section{AIM}

- To highlight the issue of vitamin D supplementation in patients with sarcoidosis.

\section{CASE REPORT}

- We report the case of a 66-year-old lady, who presented with a oneweek history of general weakness, drowsiness, nausea and confusion.

- 6 weeks prior to presentation, she underwent right-sided intramedullary nail insertion for a traumatic femur fracture, whilst abroad.

- Her past medical history includes stage IV pulmonary sarcoidosis, pulmonary hypertension and vitamin D deficiency.

- Immediately post-operatively, she was started on calcium and vitamin $D$ supplement including calcitriol $(0.25 \mu \mathrm{g}$ daily) and cholecalciferol $(60,000 \mathrm{IU}$ twice weekly).

- On examination, she was clinically dehydrated with a blood pressure of 105/52 and sinus tachycardia of 110 beats per minute. She had bibasal crepitations on chest auscultation. Examination of neurological and Gl systems was unremarkable.

- Initial investigations revealed adjusted calcium of $5.35 \mathrm{mmol} / \mathrm{L}$ (NR 2.2-2.6), Phosphate $1.33 \mathrm{mmol} / \mathrm{L}$ (NR 0.8-1.5), creatinine 342 $\mu \mathrm{mol} / \mathrm{L}$ (baseline $70 \mu \mathrm{mol} / \mathrm{L}$ ), Urea 17.2mmol/L, PTH $1.2 \mathrm{pmol} / \mathrm{L}$ (NR 1.1-6.8). ECG showed sinus tachycardia with a cQT of $480 \mathrm{msec}$. Four months prior to presentation, 25 hydroxy-vitamin D (25(OH)D) level was $24.6 \mathrm{nmol} / \mathrm{L}$ (NR 70-150).

- Her hypercalcaemia was felt to be secondary due to Vitamin $D$ toxicity on the background of sarcoidosis. She was admitted to HDU, where she was treated with aggressive fluid resuscitation, increased dose of glucocorticoids, Calcitonin and diuretics, with subsequent clinical and biochemical improvement (Chart 1).

- The result of $25(\mathrm{OH}) \mathrm{D}$ level came back raised at $390 \mathrm{nmol} / \mathrm{L}$.

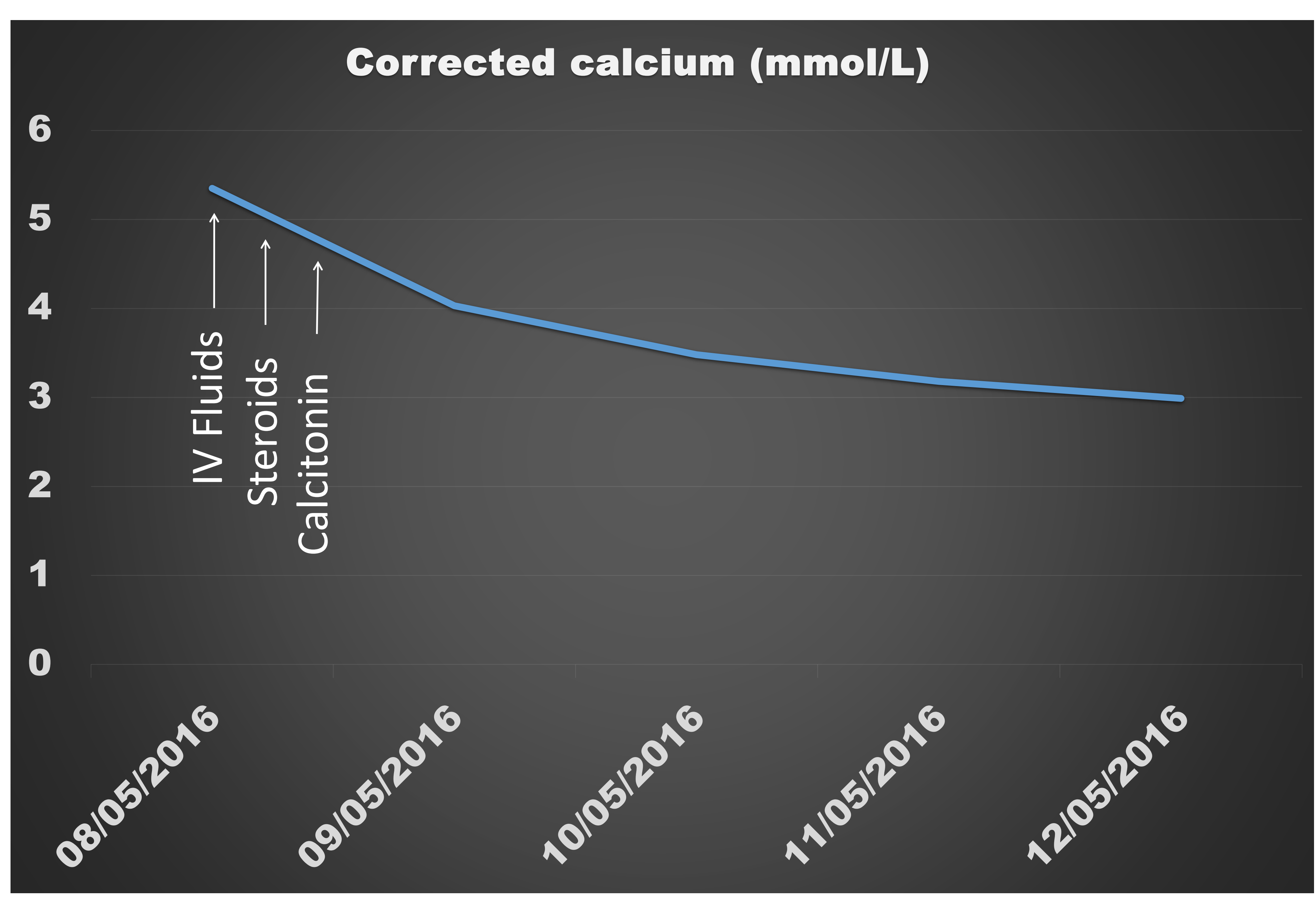

Chart 1: Corrected calcium following treatment

\section{DISCUSSION}

- In patients with sarcoidosis, Interferon gamma-mediated inflammation results in stimulation of 1 a-hydroxylase enzyme, which is responsible for the conversion of $25(\mathrm{OH}) \mathrm{D}$ to active $1,25(\mathrm{OH})_{2} \mathrm{D}_{3}$

- This can result in adequate $1,25(\mathrm{OH})_{2} \mathrm{D}_{3}$ levels with insufficient 25(OH)D. Therefore, pharmacological vitamin D supplementation in patients diagnosed with vitamin $D$ deficiency, based on $25(\mathrm{OH}) \mathrm{D}$ measurement, can potentially increase the risk of hypercalcaemia secondary to vitamin $\mathrm{D}$ toxicity.

- In one small RCT, Vitamin D supplementation had no benefit on surrogate markers of skeletal health and caused one case of significant hypercalcaemia.

\section{CONCLUSION}

- This case highlights the importance of practising caution when prescribing vitamin D particularly in patients with a background of granulomatous diseases.

- Measurement of active form of vitamin $D$ in those patients should be considered.

\section{REFERENCES}

Sage RJ et al. J Am Acad Dermatol. 2011 Apr;64(4):795-6.

2. Bolland MJ et al. BMJ open. 2013 Oct 23;3(10):e003562.

3. Kamphuis LS et al. JBMR. 2014 Nov;29(11):2498-503. 